University of Nebraska - Lincoln

DigitalCommons@University of Nebraska - Lincoln

1982

\title{
A Management Science Approach to Contingency Models of Organizational Structure
}

\author{
Sang M. Lee \\ University of Nebraska-Lincoln \\ Fred Luthans \\ University of Nebraska - Lincoln, fluthans1@unl.edu \\ David L. Olson \\ Texas A\&M University
}

Follow this and additional works at: https://digitalcommons.unl.edu/managementfacpub

Part of the Business Administration, Management, and Operations Commons, Management Sciences and Quantitative Methods Commons, and the Strategic Management Policy Commons

Lee, Sang M.; Luthans, Fred; and Olson, David L., "A Management Science Approach to Contingency Models of Organizational Structure" (1982). Management Department Faculty Publications. 236.

https://digitalcommons.unl.edu/managementfacpub/236

This Article is brought to you for free and open access by the Management Department at DigitalCommons@University of Nebraska - Lincoln. It has been accepted for inclusion in Management Department Faculty Publications by an authorized administrator of DigitalCommons@University of Nebraska - Lincoln. 


\title{
A Management Science Approach to Contingency Models of Organizational Structure
}

\author{
SANG M. LEE \\ FRED LUTHANS \\ University of Nebraska \\ DAVID L. OLSON \\ Texas A\&M University
}

This study demonstrates the applicability of a quantitative modeling approach, specifically goal programming, in operationalizing the relationship between environmental variables and specific organizational structural variables for optimal goal attainment. A goal programming model is developed to analyze and determine the optimal relationships for goal attainment.

The contingency approach has emerged in recent years as the dominant theoretical framework for viewing organizational structure and design. Although open systems analysis (Katz \& Kahn, 1966) emphasized the input of the external environment into organization structuring, the contingency approach attempts to establish functional relationships between environmental variables and organizational variables. Over the past decade and a half, contingency theorists have demonstrated the apparent interaction between the environment and organization variables. For example, more than 15 years ago the pioneering contingency theorist Joan Woodward (1965) found that the environmental variable of technology seemed to have a relationship with structural variables. Although she dealt with relatively narrow production oriented (unit, mass/batch, and process) technology, Perrow (1970) and others have since suggested that other technological classifications such as knowledge based variables are related to organizational structure variables.

Perhaps the best known contingency approach comes from the work of Lawrence and Lorsch (1967). Using 10 firms in 3 industries, they analyzed how differences in the external environments were related to differences in the internal environments and how these, in turn, were related to the integrating mechanisms of the organization. They found that the more turbulent, diverse, and complex the external environment, the more differentiated (in terms of goals, time perspective, interpersonal orientation, and 
formality of structure) were the subunits or departments, and the greater the need for elaborate integrating mechanisms.

More recently, the Lawrence and Lorsch contingency approach has been extended into what is generally called an information processing view of organizations. For example, Galbraith $(1973,1977)$ feels that as organizations become more complex and face increasing environmental uncertainty, they become more differentiated, which in turn causes an imbalance with the existing organizational integrating mechanisms and a breakdown in the necessary information processing needed for successful performance. To restore the balance between differentiation and integration, the organization must either reduce its need to process information or increase its capacity to process information.

This brief overview of contingency organization theory points out the importance, but also the problem, of relating a number of environmental variables with organizational structural variables. Contingency organization theorists certainly have recognized the importance and have been able to identify many of the environmental variables and structural variables that impact on organizational effectiveness. For example, a good summary list of environmental variables is provided by Pugh, Hickson, Hinings and Turner (1969) as follows: (1) origin and history; (2) ownership and control; (3) size; (4) charter; (5) technology; (6) location; (7) resources; and (8) dependence. In addition, these theorists consider functional specialization, subordinate ratio, the percentage of clerks, the percentage of nonworkflow personnel, and vertical span as structural variables, and efficiency as a performance variable. As another example, Blau (1970) proposed that larger organizational size promotes structural differentiation and that as the size of an organization increases, the marginal influence of size on differentiation decreases. This was expected because the need for efficiency gained by division of labor was offset to some degree by the added need for coordination inherent in large size. The more effort necessary for the attainment of organizational objectives, the larger the size required. But larger size, in turn, requires additional means of control. The larger an organization, the more isolated are its subelements, which implies higher degrees of vertical differentiation and layers of organization hierarchy to coordinate subelements.

In addition to the variables identified by Pugh et al. and the impact of size that Blau has stressed, other variables, such as span of control and administrative ratios, have been suggested to have contingency implications. Bell (1967) has suggested that humans have limited capacity to direct the activities of others. The more similar the tasks assigned to an organizational subunit, the more people an individual might be able to keep track of in the span of control. Administrative ratios are used to measure the degree of control used to direct organizational activities. For example, direct supervisory control can be measured by the ratio of supervisors to the number of productive personnel. An alternative means of controlling organizational activity might be the use of professionally trained individuals. 
This method of control relies on the inherent professional judgment of specialists in the performance of organizational tasks. A third means of control might be the use of clerical personnel. These individuals would not rely on personal judgment in the administration of organizational activities, but rather on standard or directed procedures. In spite of the ability of the contingency theorists to identify the variables as discussed above, however, the method for a meaningful operationalization of the relationship between environmental variables and structural variables in the pursuit of attaining the goal of organizational effectiveness has yet to be addressed.

This paper suggests that an overlooked, but potentially very useful, way of operationalizing contingency organization theory is through quantitative modeling techniques. Quantitative methods have been very successful in dealing with what Simon (1960) has called structured problems. Structuring in this sense means the establishment of variable relationships in a sufficiently accurate manner to obtain useful conclusions. The act of developing a mathematical model is itself an example of structuring. The well-defined relationships are easiest to model, and physical relationships can be established with precise accuracy. But modeling also can be used to learn more about the structure of more elusive relationships, such as those suggested by the contingency organization theorists.

Lindblom (1959) and Hirschman and Lindblom (1962) proposed that knowledge can be gained by successive descriptions of a system, with adjustments of theory made in light of further experience. Simon (1979) and March (1978) proposed that managers make decisions in light of the bounded rationality of their existing knowledge. It is in this spirit that this paper seeks to demonstrate that quantitative modeling techniques can operationalize the contingent relationships between environmental and structural variables aimed at attaining goal optimization.

\section{Development of the Model}

To demonstrate the use of modeling techniques for contingency organization theory, a set of data was collected from tables of organization and equipment (T.O.E.) for 52 U.S. Army standard organizations. This type of organization was selected because, as Childers, Mayhew, and Gray (1971) have pointed out, it has data readily available and, unlike many other organizations in U.S. society, the military designs organizations specifically for effectiveness.

\section{Variables}

The variables chosen for the model closely follow those cited by Pugh et al. (1969). The final list of variables was modified because the military organizations studied had common origin, ownership, charter, and dependence. Also, organizational location and resources were independent of design. Briefly summarized, the following variables are used: 
1. SIZE, defined as the number of individuals assigned to each organization, ranges from 10 to 888 .

2. TASKS are defined as the number of military occupational specialties presented in a unit regardless of rank.

3. LEVEL is the hierarchical level of the unit. The five levels possible are (1) squad, (2) section, (3) platoon, (4) company, and (5) battalion.

4. AUTO (automation) is measured as the number of motor vehicles assigned to a unit per 100 personnel. Dividing vehicles by personnel provides a ratio, thus controlling for size. The measure is imperfect because vehicle quality is not considered. In reality, a jeep does not provide the same degree of automation as a helicopter. Although this results in a few cases in which the measure does not accurately reflect true automation, it does provide a usable general measure.

5. SPAN (span of control) reflects the number of subordinate command elements, not including staff personnel.

6. CMDRAT (command ratio) is the number of command personnel per 100 line personnel assigned. Command personnel have supervisory responsibility, with authority to direct the activities of subordinates.

7. PRORAT (professional ratio) is the number of professional personnel per 100 line personnel. Professional personnel are defined as those assigned to duties calling for specialized training with staff responsibilities.

8. CLERAT (clerical ratio) is the number of administrative personnel other than command or professional per 100 line personnel.

9. EFFECT is a subjectively assigned estimate of unit ability to accomplish organizational missions. A scaled measure was obtained considering equipment, mix of types of units, and consideration of the increased effectiveness of military units due to control and communication facilities found in headquarters.

The data used in the study, data parameters, and covariance and correlation matrices are available from the senior author.

\section{Relating the Variables}

The purpose of this paper is to present a method of utilizing contingent organizational relationships. A key link in this process is statistical analysis of these relationships. It is contended that many of the variables in organization theory are interrelated. Therefore, a description of the relationship among variables in one equation may be contingent on the relationships among variables in other equations. A simultaneous set of relationships could be used to describe this system.

When simultaneous systems of equations are used based upon statistical data, in order for ordinary least squares to be valid there must be no relationship between the error terms across equations. And error terms must 
not covary with any of the independent variables. But in the contingent system proposed, such covariance across equation error terms is expected.

Three-stage least-squares estimation (Zellner \& Theil, 1962) is a generalized-least-squares estimating procedure that corrects for contemporaneous correlation in a simultaneous-equation system. Pindyck and Rubinfeld (1976) point out that ordinary-least-squares estimation of simultaneous-equation systems is inconsistent and biased. Two-stage least squares provides consistent single-equation parameter estimates, but these estimates are still biased. Although three-stage least squares is a more costly method, it can provide consistent, unbiased parameter estimates. Madansky (1964) found three-stage least squares to be more efficient than twostage least squares.

An iterative three-stage least-squares estimation involves estimating the reduced form of the simultaneous system, obtaining residuals for each equation. These residuals then are used to obtain the variance-covariance matrix of error terms. The iterative procedure repeats this step until convergence. The last stage of the procedure is to obtain generalized least square equation estimates.

The correlation matrix of the variables used indicates that size, tasks, level, and effects have strong correlations $(r=.723-.953)$ for this set of data. Therefore, these variables were not jointly included as independent variables in any of the simultaneous equations.

\section{Modeling Relationships}

Mathematical programming methods have been developed that allow analysis and optimization of systems of relationships. Linear programming models have proven useful in dealing with simultaneous systems. Linear programning, however, requires consideration of only one objective function.

The extension of linear programming models to models capable of considering multiple objective functions also has been well developed. Charnes and Cooper (1961) reviewed some early applications. Lee (1972) presented the concept of goal programming and operationalized it through the modified simplex method. Although linear programming seeks the optimization of a single objective function, goal programming approaches seek to minimize deviations from the desired goal achievement levels. This approach allows consideration of a multitude of objectives. - Linear programming models are unable to deal with directly conflicting constraints, but goal programming seeks to satisfice multiple objectives according to the priority system of the decision maker. Each objective is satisfied in turn until a direct conflict occurs. When a direct conflict is present, the goal programming model selects the solution minimizing the deviation from the lower priority goal while ensuring satisfaction of goals with higher priority. 


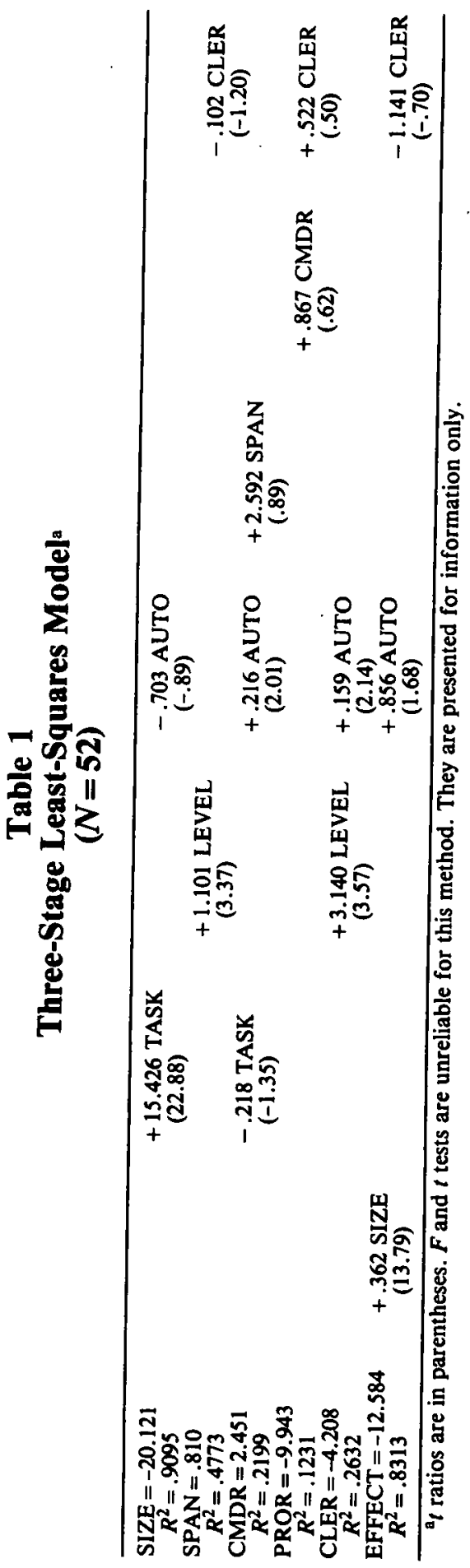


The goal programming model can deal with a variety of goal forms. One type of goal would be to maximize or minimize some criterion variable. Minimization of organization size or maximization of organization effectiveness would be an example of this type of goal.

Many managerial goals do not require optimization for satisfaction. Charnes and Cooper (1961) applied constrained optimization methods in the analysis of a system. Charnes, Cooper, Harold, Karwan, and Wallace (1976) presented the technique of replacing exact values in constraints with ranges. In effect, this type of goal would be satisfied by variable values falling within the ranges selected rather than an extreme solution. An example of this type of goal would be to obtain a specified interval for average span of control.

The benefit of goal programming flexibility is most apparent when considering sets of desirable goals for the same variable. A high priority may be placed on satisfaction of a loose, satisficing level for a particular variable, such as degree of automation. At a lower priority, the model could include tighter restrictions on this variable, which would be satisfied only if intermediate priority goals could be satisfied at the same time.

\section{The Goal Programming Model}

For demonstration purposes, the data are used to develop a goal programming model to aid in the design of an organization, given a varying number of unique job descriptions (tasks), hierarchical level, and range of automation. These would be environmental variables, exogenous to the system. Organization design variables include size (the number of people assigned), span of control, and the three administrative ratios.

The proposed contingency application assumes that it would be desirable to have organization design variables fit the regressed model relationships. This assumes that the data come from standard organizations, designed on the basis of experience and proven effectiveness.

It also would be desirable to maximize expected effectiveness. Size should be minimized, to accomplish assigned tasks with minimal resources. The span of control should fall within traditional limits. Automation provides a means of substituting capital for labor and often provides an alternative source of organization capability. Generally, increased automation involves increased capital expenditure, and increased size often may involve increased operating expense. Therefore, it may be desirable to have the level of automation fall within prescribed bounds. The use of directors, professionals, and clerical personnel in organizational control also may call for desirable bounds. Organizations often have been considered sluggish when overloaded with administrative overhead. It also would be beneficial to keep professional and clerical ratios as low as possible because these resources often are scarce. 


\section{Goals and Priorities}

The goals described above may be in conflict. Maximizing effectiveness may conflict with the minimization of size and limits on automation and administrative ratios. Goal programming requires management to rank goals by priority. One possible set of goals, in order of priority, is presented.

Structural. An implied goal would be to satisfy the simultaneous-equation system obtained. In addition, input values for environmental variables must be met. The first priority of the model would be to satisfy all structural constraints. In the model presented in Table 2, the first six constraints describe the simultaneous equations obtained from regression. Equation 7 inputs the number of unique tasks required. Equation 8 inputs the hierarchical level. Equations 9 and 10 enter the upper and lower bounds on automation.

Priority 1. The first discretionary goal in the model would be to have the average span of control fall between three and five. This would be accomplished by having the positive deviation from equation 11 and the negative deviation from equation 12 be zero.

Priority 2. The second goal is to maintain size at 250 or less. This goal would be accomplished if $d_{13}^{+}$were minimized to zero.

Priority 3. The third goal would be that administrative ratios be limited. Specific upper limits included are a maximum desired command ratio of 15 per 100 line personnel, a professional ratio no more than 8 , and a clerical ratio no more than 10 . These goals would be satisfied if $d_{14}^{+}, d_{15}^{+}$, and $d_{16}^{+}$were all zero.

Priority 4. The fourth goal would be to have the level of automation fall within 20 and 30 vehicles per 100 personnel. This goal would be satisfied if $d_{17}^{+}$and $d_{18}^{-}$were both minimized to zero.

Priority 5. The fifth goal is to maximize effectiveness, as measured in the model. This goal is included by setting variable $X_{9}$ equal to an unreachable number $M$, and minimizing the negative deviation, $d_{19}^{-}$.

Priority 6. The sixth goal is to minimize size. Equation 20 sets size, $X_{1}$, equal to zero, and goal dissatisfaction is measured by $d_{20}^{+}$. Although the fifth goal may result in an extreme solution to the model, the sixth goal may have an impact if alternative sizes resulted in equal effectiveness.

\section{Constraints}

Table 2 presents the goal programming model. The first six constraints provide the structure identified by the three-stage least-squares model. 


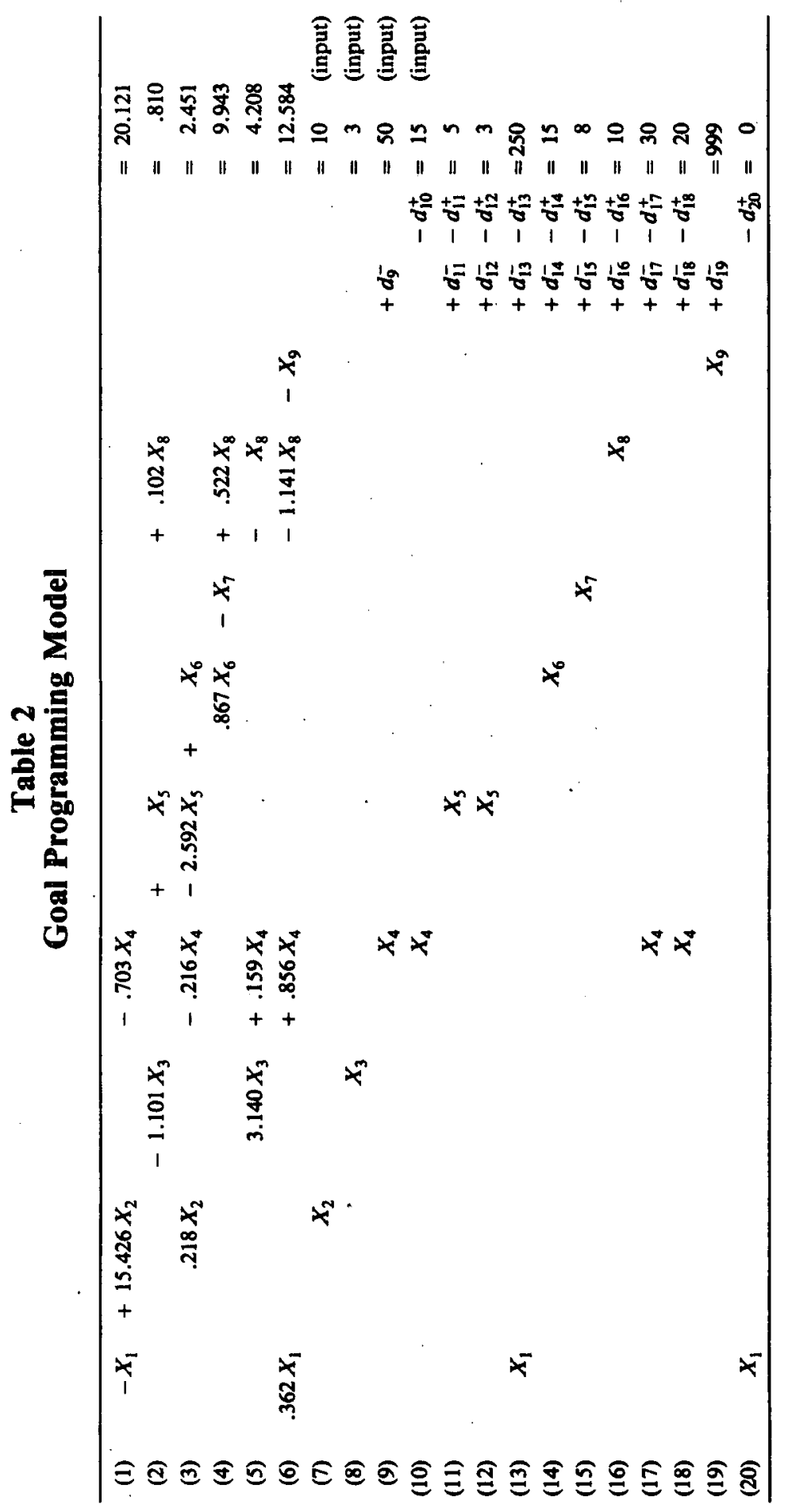




\section{The Objective Function}

The objective function in goal programming is to minimize deviational variables in order of priority. Structural requirements are forced by omitting violating deviational variables from the model. For the set of goals presented above, the objective function would be:

$$
\begin{aligned}
\operatorname{Min} Z= & P_{1}\left(d_{11}^{+}+d_{11}^{-}\right)+P_{2} d_{13}^{+}+P_{3}\left(d_{14}^{+}+d_{15}^{+} d_{16}^{+}\right)+P_{4}\left(d_{17}^{+}+d_{18}^{+}\right) \\
& +P_{5} d_{19}^{-}+P_{6} d_{20}^{+}
\end{aligned}
$$

This objective function could be modified to examine model results for any combination of managerial goals in any order desired. Should the decision maker desire a different order of goals, priority levels could be rearranged.

\section{Model Results}

The model was run with the goal structure described above for varying numbers of tasks at hierarchical levels 3,4 , and 5 . The results of these runs are presented in Table 3.

The simultaneous-equation model allows consideration of contingent interaction in a complex system. Individual-equation models allow more detailed and precise analysis of any one variable, assuming that all other variables are held constant. Unfortunately, life involves almost no constancy. Therefore, a simultaneous description of a system is highly useful in assessing the impact of changes in variable levels.

The goal programming model provides a flexible, responsive structure that allows the decision maker to include any number of desirable goals. The goal structure presented gives first priority to obtaining a span of control between 3 and 5. At level 3, this is not a binding constraint for lower numbers of tasks. At a task level of 20, however, this constraint is binding. A more detailed review of the final goal programming simplex tableau would reveal the other goals impacted by this constraint. The second goal of limiting size to 250 also is not binding at level 3 until 20 tasks are required.

Automation in this model is an alternative means of obtaining effectiveness (equation 6). But increasing automation causes a decrease in size and an increase in the number of supervisors (command ratio-equation 3) and clerical personnel (equation 5). The interacting complexities of the model lead to a situation in which seeking to obtain a goal by manipulating one control variable has unforeseen consequences. The goal programming model provides a means of keeping track of all of these complexities, allowing a means of assuring compliance with higher priority goals.

Consideration of the single goal of maximizing effectiveness would yield the result shown in Table 4 . This result can be compared with that 


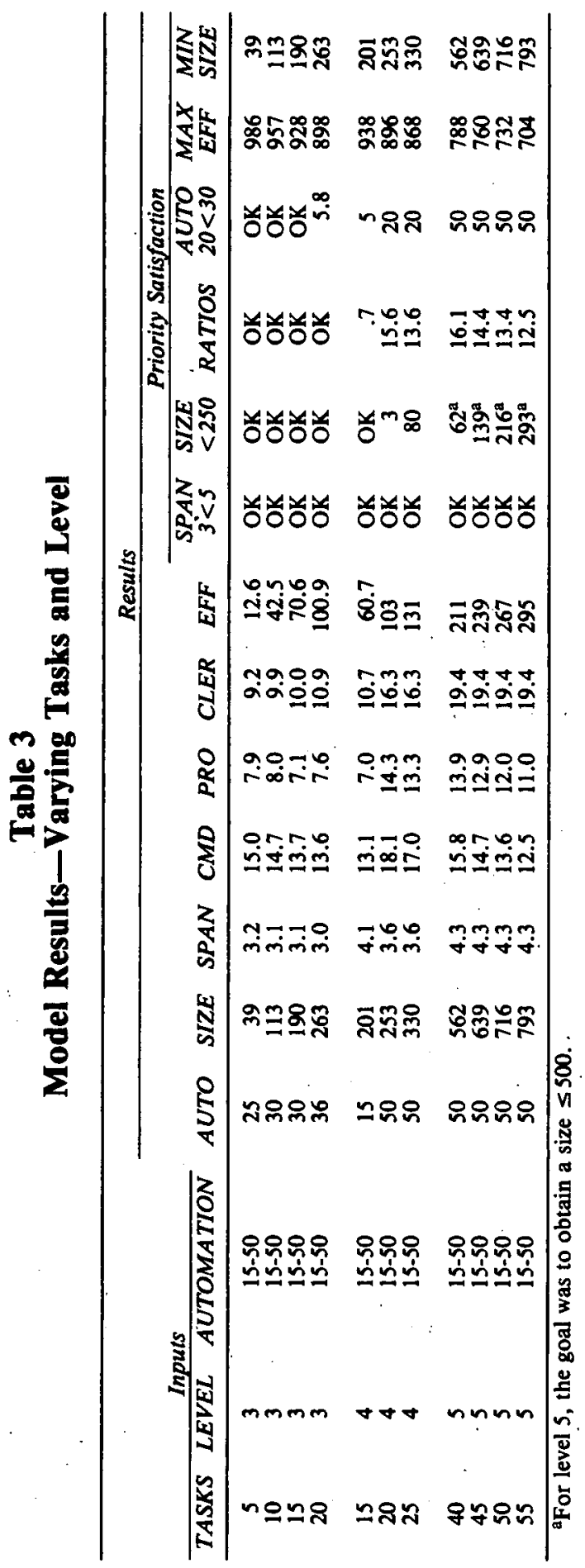




\section{Table 4}

\section{Single Goal-Maximize Effectiveness}

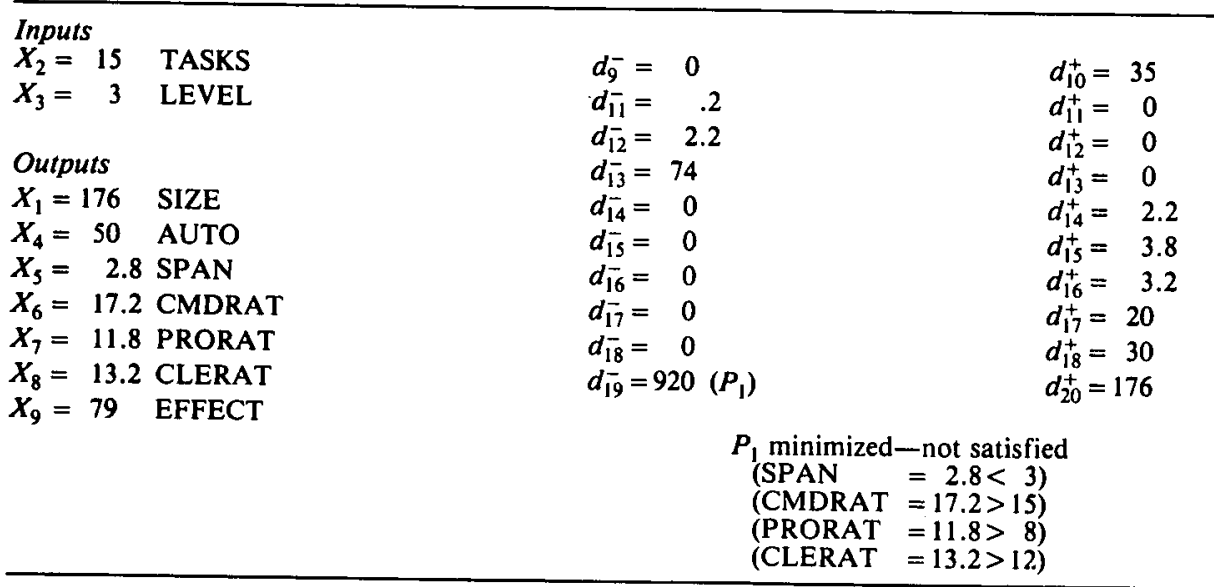

Table 5

Six Goals

\begin{tabular}{|c|c|c|c|c|}
\hline 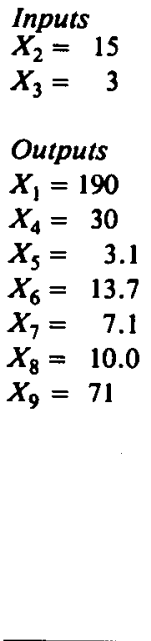 & $\begin{array}{l}\text { TASKS } \\
\text { LEVEL } \\
\\
\text { SIZE } \\
\text { AUTO } \\
\text { SPAN } \\
\text { CMDRAT } \\
\text { PRORAT } \\
\text { CLERAT } \\
\text { EFFECT }\end{array}$ & $\begin{array}{l}d_{9}^{-}=20 \\
d_{11}^{-}=1.9 \\
d_{12}^{-}=0\left(P_{1}\right) \\
d_{13}^{-}=60 \\
d_{14}^{-}=1.3 \\
d_{15}^{-}=.9 \\
d_{16}^{-}=2.0 \\
d_{17}^{-}=0 \\
d_{18}^{-}=0\left(P_{4}\right) \\
d_{19}^{-}=928\left(P_{5}\right) \\
P_{1} \text { SATISFIED } \\
P_{2} \text { SATISFIED } \\
P_{3} \text { SATISFIED } \\
\\
P_{4} \text { SATISFIED } \\
P_{5} \text { NOT SATISF } \\
P_{6} \text { NOT SATISF }\end{array}$ & $\begin{array}{l}\text { 3<SPAN } \\
\text { SIZE } \\
\text { CMDRAT } \\
\text { PRORAT } \\
\text { CLERAT } \\
\text { 20<AUTO } \\
\text { FIED-EFFECT } \\
\text { FIED-SIZE MIN }\end{array}$ & $\begin{array}{l}d_{10}^{+}=15 \\
d_{11}^{+}=0\left(P_{1}\right) \\
d_{12}^{+}=0.1 \\
d_{13}^{+}=0\left(P_{2}\right) \\
d_{14}^{+}=0\left(P_{3}\right) \\
d_{15}^{+}=0\left(P_{3}\right) \\
d_{16}^{+}=0\left(P_{3}\right) \\
d_{17}^{+}=0\left(P_{4}\right) \\
d_{18}^{+}=10 \\
d_{20}^{+}=190\left(P_{6}\right) \\
=3.1<5 \\
=190<250 \\
=13.7<15 \\
=7.1<8 \\
=10.0<12 \\
=10 \leq 30 \\
=30 \leq 4 \\
\text { MAXIMIZED } \\
\text { JIMIZED }\end{array}$ \\
\hline
\end{tabular}

obtained for six goals, with the same number of tasks and levels, shown in Table 5.

The cost of placing maximum effectiveness as measured in this model above all other goals would be loss of desired span of control, and administrative ratios higher than desired.

The concept presented in this paper involves three critical steps. The method would require a theoretically sound set of variables, measured by sound statistics. The relationship among variables would need to consider 
statistical assumptions, and the model should reflect the actual goals of the organization. The model would provide a framework within which decision makers could evaluate organizational goals.

The example presented is for illustrative purposes. Therefore, it should be considered as a prototype for a model of a complex system of interrelated, contingent variables. It is felt that a combination of methods as presented enables consideration of more complex systems than present methods allow.

\section{Conclusion}

The goal programming modeling approach to contingency organization design suggested here is highly adaptable to changes in parameters. Confidence ranges for each of the dependent variables can be adjusted, and the priority structure can be readily modified. Utilizing such a quantitative modeling approach, contingency organization theory can be effectively operationalized by:

1. obtaining appropriate environmental and structural variables from existing and developing organization theory;

2. obtaining a logical system of relationships between those variables from the quantitative modeling techniques;

3. developing a specific model capable of optimizing structural variables given environmental variables;

4. implementing the model into actual practice.

Ackoff (1974), Grayson (1973), and others have proposed that quantitative methods are most effective when they seek specific problem solutions rather than blanket applications. It follows that application of quantitative methods for operationalizing contingency organizational relationships should be on the basis of specific model selection to solve the problem at hand rather than seeking to force problem solution by preselected models. Therefore, although the proposed modeling approach suggested in this paper demonstrates the potential for the analysis of contingency organizational relationships, it is not implied that this specific method is approriate for every contingency application. Goal programming, however, has proven flexible in analyzing various systems of relationships. In addition, simultaneous models provide consideration of complex systems, such as found in contingency organizational theory. There seems little question that by merging seemingly diverse fields such as organization theory and quantitative modeling, the ultimate goal of both-notably more effective organizations-can be better accomplished than by either one singly.

\section{References}

Ackoff, R. L. Beyond problem solving. Decision Sciences, 1974, 5(2), x-xv.

Bell, G. D. Determinants of span of control. American Journal of Sociology, 1967, 73, 100-109.

Blau, P. A formal theory of differentiation in organizations. American Sociological Review, 1970, 35 , 210-218. 
Charnes, A., \& Cooper, W. W. Management models and industrial applications of linear programming. New York: John Wiley \& Sons, 1961.

Charnes, A., Cooper, W. W., Harold, J., Karwan, K. R., \& Wallace, W. A. A goal interval programming model for resource allocation in a marine environmental protection program. Journal of Environmental Economics and Management, 1976, 3, 347-362.

Childers, G. W., Mayhew, B. H., Jr., \& Gray, L. N. System size and structural differentiation in military organizations: Testing a baseline model of the division of labor. American Sociological Review, 1971, 76, 813-830.

Galbraith, J. Desgining complex organizations. Reading, Mass.: Addison-Wesley, 1973.

Galbraith, J. Organization design. Reading, Mass.: Addison-Wesley, 1977. Grayson, C. J., Jr. Management science and business practice. Harvard Business Review, 1973, 51(4),
41-48.

Hirschman, A. O., \& Lindblom, C. E. Economic development, research and development, policy making: Some converging views. Behavioral Science, 1962, 7(2), 211-222.

Katz, D., \& Kahn, R. L. The social psychology of organizations. New York: Wiley, 1966.

Lawrence, P. R., \& Lorsch, J. W. Organization and environment. Boston: Division of Research, Harvard Graduate School of Business Administration, 1967.

Lee, S. M. Goal programming for decision analysis. Philadelphia: Auerbach Publishers, Inc., 1972. Lindblom, C. W. The science of muddling through. Public Administration Review, 1959, 19(2),
79-88.

Madansky, A. On the efficiency of three-stage least squares estimation. Econometrica, 1964, 32, 55.

March, J. G. Bounded rationality, ambiguity, and the engineering of choice. The Bell Journal of Eco-
nomics, 1978, 9(2), 587-608.

Perrow, C. Organizational analysis: A sociological view. Belmont, Cal.: Wadsworth, 1970.

Pindyck, R. S., \& Rubinfeld, D. L. Econometric models and economic forecasts. New York: McGraw-Hill Book Co., 1976.

Pugh, D., Hickson, D., Hinings, C., \& Turner, C. The context of organization structures. Administrative Science Quarterly, 1969, 14, 91-114.

Simon, H. A. The new science of management decision. New York: Harper \& Row, 1960. Simon, H. A. Rational decision making in business organizations. The American Economic Review,
1979, 69(4), 493-513.

Woodward, J. Industrial organization. London: Oxford, 1965.

Zellner, A., \& Theil, H. Three-stage least squares estimation. Econometrica, 1962, 30, 54-78.

Sang $M$. Lee is Regents Distinguished Professor of Management and Chairman of the Department of Management, University of Nebraska.

Fred Luthans is Regents Professor of Management, University of Nebraska.

David L. Olson is Assistant Professor of Business Analysis and Quantitative Systems, Texas A\&M University. 